NASA Technical Memorandum 102089

\title{
Distortion and Regulation Characterization of a Mapham Inverter
}

Richard C. Sundberg

General Dynamics.

Space Systems Division

San Diego, California

Andrew S. Brush

Sverdrup Technology, Inc.

NASA Lewis Research Center Group

Cleveland, Ohio

Robert M. Button

National Aeronautics and Space Administration

Lewis Research Center

Cleveland, Ohio

and

Alexander G. Patterson

Analex Corporation

Lewis Research Center

Cleveland, Ohio

Prepared for the

24th Intersociety Energy Conversion Engineering Conference cosponsored by the IEEE, AIAA, ANS, ASME, SAE, ACS, and AIChE Washington, D.C., August 6-11, 1989

\section{NMSA}

(NASA-TM-102089) DISTORT ION AND REGULATION

N $89-26148$

CHARACTER IZATION OF A MAPHAM IN VERTER

iNASA. Lewis Research (enter) 10 pCSCL 090 


\title{
Distortion and Regulation Characterization of a Mapham Inverter
}

\author{
Richard C. Sundberg, General Dynamics Space Systems Division, San Diego, CA 92138 \\ Andrew S. Brush, Sverdrup Technology, Inc., NASA Lewis Research Center Group, Cleveland, OH 44135 \\ Robert M. Button, NASA Lewis Research Center, Cleveland, OH 44135 \\ Alexander G. Patterson, Analex Corporation, Lewis Research Center, Cleveland, OH 44135
}

\begin{abstract}
Output voltage total harmonic distortion (THD) of a $20 \mathrm{kHz}$, 6kVA Mapham resonant inverter is characterized as a function of its switching-to-resonant frequency ratio, $\mathrm{f}_{\mathrm{S}} / \mathrm{f}_{\mathrm{T}}$, using the EASY5 Engineering Analysis System. EASY5 circuit simulation results are compared with hardware test results to verify the accuracy of the simulations. The effects of load on the THD versus $f_{S} / f_{r}$ ratio is investigated for resistive, leading, and lagging power factor load impedances. The effect of the series output capacitor on the Mapham inverter output voltage distortion and inherent load regulation is characterized under loads of various power factors and magnitudes. An optimum series capacitor value which improves the inherent load regulation to better than $3 \%$ is identified. The optimum series capacitor value is different than the value predicted from a modeled frequency domain analysis. An explanation is proposed which takes into account the conduction overlap in the inductor pairs during steady-state inverter operation, which decreases the effective inductance of a Mapham inverter. A fault protection and current limit method is discussed which allows the Mapham inverter to operate into a short circuit, even when the inverter resonant circuit becomes overdamped.
\end{abstract}

\section{INTRODUCTION}

$20 \mathrm{kHz}$ AC power distribution is currently baselined for use on the Space Station Freedom, and is under consideration for launch vehicles and aircraft utilizing compact and lightweight electro-mechanical actuators. The advantages of high frequency $\mathrm{AC}$ power distribution have been discussed in the literature [1][2]. To convert spacecraft photovoltaic, battery, solar dynamic, or other energy sources into $20 \mathrm{kHz}$ power, lightweight and efficient inverters with regulated, low-distortion outputs are required. A leading candidate is the Mapham inverter. The Mapham inverter uses resonant conversion, which results in the highest possible full load efficiency because of the lack of frequency sensitive turn-off losses.

To minimize Electro-Magnetic Interference (EMI) in $20 \mathrm{kHz}$ distribution systems, the Mapham inverter must be designed to achieve minimum output voltage distortion. It has been shown that the Mapham inverter output voltage total harmonic distortion (THD) is related to its switching-to-resonant frequency ratio, or nornalized switching frequency $f_{\mathrm{sn}}[3]$. However, a quantified relationship had not been identified, nor had the effects of load and power factor on the relationship been identified. Section 3 of this paper presents the results of circuit simulations which characterize the THD versus $f_{S n}$ function, and the effects of load magnitude and power factor on that function.
Although active phasor-regulation of a series-output connected inverter pair (see figure $2-1 \mathrm{~b}$ ) has been shown to provide near perfect line and load regulation [4][5], the inherent load regulation of a single Mapham inverter module is important for practical reasons. To realize maximum efficiency in a seriesoutput connection, the regulation angle $\varnothing$ in figure $2-1 \mathrm{c}$ should be near zero at full load [6]. However, at $\emptyset \sim 0^{\circ}$ the inverter pair output must maintain regulation under worst-case voltage drop conditions for the vectors $\mathbf{V}_{01}$ and $\mathbf{V}_{02}$. Since inductive loads result in worst-case voltage drop in an uncompensated Mapham inverter, the regulation angle of $\varnothing \sim 0$ must be reserved for lagging power factor loads to maintain a constant output voltage $v_{O T}$. This will result in a large value of $\emptyset$ at unity power factors and a decrease in inverter pair efficiency. Thus, if the Mapham inverter inherent load regulation could be improved, the regulation angle could remain near zero at all power factors, which would improve the inverter pair efficiency. It has been shown that the inherent load regulation can be improved by placing a capacitor in series with the load $\left(C_{S}\right.$ in figure 2-1a). The optimum series capacitor value for best load regulation has been analytically determined from frequency domain analysis [7][8]. However, hardware testing has revealed that series capacitor values larger than the predicted value result in belter inherent load regulation [6]. Thus the optimum series capacitor value from a regulation point of view needed further investigation.

The series output capacitor has also been shown to effect output voltage distortion[6]|8|, efficiency[6], and short circuit operation[3][6]. However, these relationships had not been well characterized. Section 4 of this paper presents the results of computer circuit simulations which characterize the effect of the series capacitor on inherent load regulation and on output voltage THD. A discussion of the effects of the series capacitor on short-circuit operation is also presented, as well as a method of limiting the short circuit output current and protecting the inverter semiconductor switches during forced commutation. Although the series capacitor affects efficiency, the circuit models used were not able to determine this relationship, therefore dicussion of it is beyond the scope of this paper.

\section{INVERTER OPERATION}

The Mapham inverter, shown in figure 2-1a, consists of four switches each with a flyback diode, four resonant inductors, a resonant capacitor $C_{T}$, a series output capacitor $C_{S}$, and an output transformer. The resonant inductors form : series-resonant circuit with the capacitor $C_{r}$. They also force each switch to turn-on and turn-off at zero current which virtually eliminates switching losses $[2 \| 3]$. The series capacitor improves load regulation $[7 \% 81$, and can also make the inverter inherently short circuit proof if small enough [3]. The output transfomer is used for load isolation and load voltage magnitude 


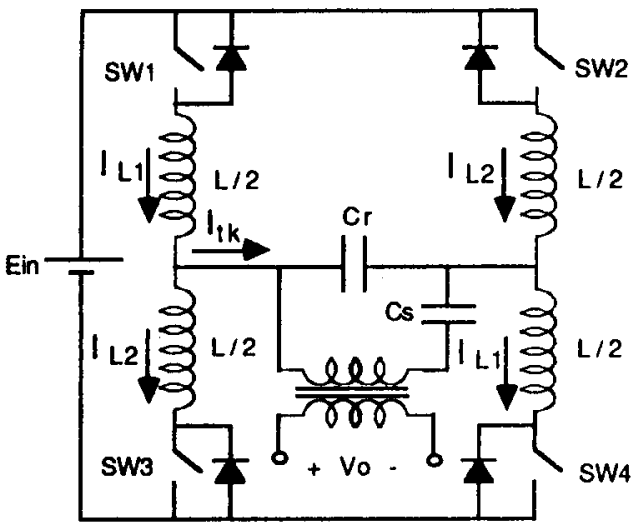

a.
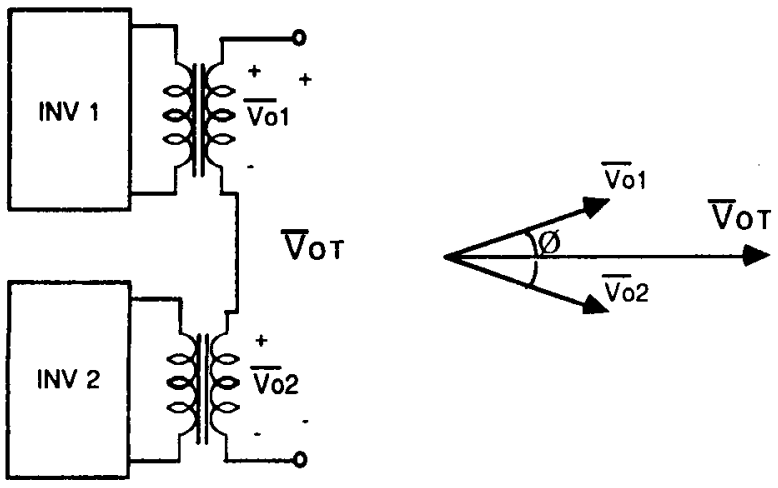

b.

c.

Figure 2-1. The Mapham inverter (a), the phasor regulated series-output connection (b), and a phasor diagram showing the vector addition of the series-output connection (c).

selection. It also allows for the series-output connection of two Mapham inverters as in the proposed Space Station Freedom Main Inverter Unit (MIU), shown in figure $2-1 \mathrm{~b}$. The seriesoutput connection doubles power output and is required for active phasor output voltage regulation, which has been demonstrated to have fast response, high efficiency, and less than $1 \%$ regulation from zero to full load over an input voltage swing of 150-200 Vdc [4][5].

Referring to figure $2-1$ a, if the switch pair $\mathrm{S} 1, \mathrm{~S} 4$ is turnedon, a sinusoidal current $I_{L 1}$ of resonant frequency $f_{r}=1 / 2 \pi \sqrt{L} C_{r}$ will flow in the resonant $L-C_{r}$ network as shown in figure $2-2$. Switches $\mathrm{S} 1$ and $\mathrm{S} 4$ commutate when $\mathrm{I}_{\mathrm{L} 1}$ reverses direction and flows through the flyback diodes of S1 and S4. If switches S2 and $S 3$ are turned-on while $I_{L 1}$ is negative, the current of $I_{L 2}$ results. The currents $I_{L 1}$ and $I_{L 2}$ sum to give the resultant resonant tank current $I_{t k}$ of frequency $f_{s}$, the switching frequency of the $S 1, S 4$ and $S 2, S 3$ switch pairs. Since each switch pair is turned on while the current of the opposite pair is negative, the switching frequency is always lower than the resonant frequency. The resonant capacitor $C_{r}$ integrates the current $I_{t k}$ to obtain the sinusoidal voltage of $V_{C}$. The load $Z_{L}$ is placed in parallel with the resonant capacitor via the output transformer, either with or without the series capacitor $\mathrm{C}_{\mathbf{s}}$.
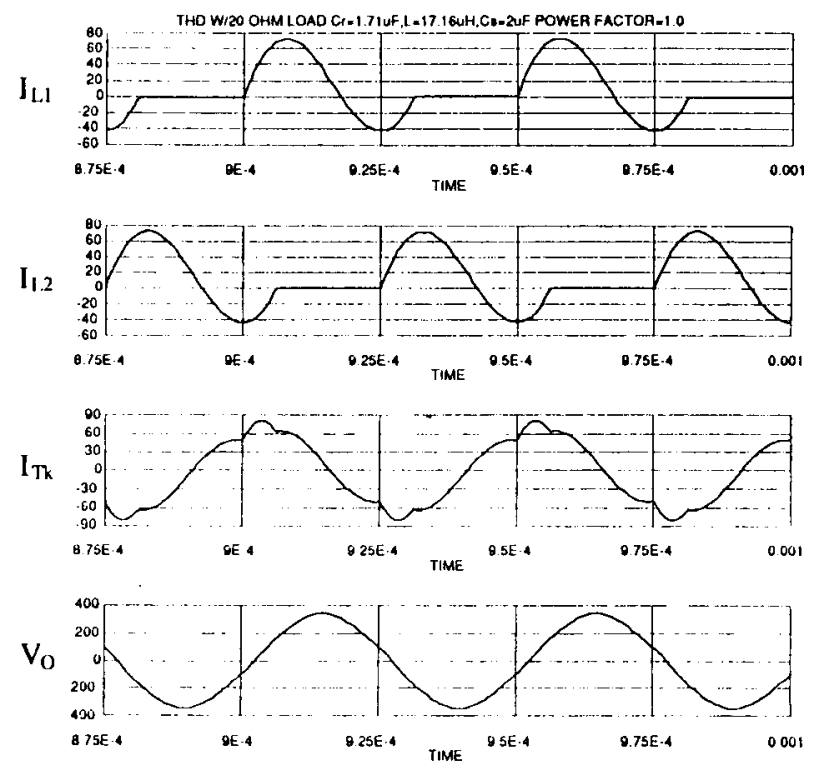

Figure 2-2. Typical Mapham inverter inductor currents, tank current, and output voltage waveforms under load.

\section{EFFECTS OF $f_{S n}$ ON INVERTER OUTPUT VOLTAGE DISTOR'TION}

To investigate the output voltage distortion of the Mapham inverter, the EASY5 Engineering Analysis System [9] was employed. The EASY5 Mapham inverter model was originally developed by Virginia Polytechnic Institute and State University, and was later modified by the NASA Lewis Researcli Center and the Rocketdyne Division of Rockwell International [10]. The inverter simulation circuit parameters were initially chosen to match the values of the Mapham inverter modules located in the NASA Lewis Research Center $25 \mathrm{~kW}, 20 \mathrm{kHz}$ Power System Testbed, developed by General Dynamics [4]. The testbed inverter modules each have a power output capability between $6 \mathrm{~kW}$ and $12 \mathrm{~kW}$ at $160 \mathrm{Vdc}$ input, depending on series capacitor value and operating point definition. After some prelininary simulations were complete, the circuit model inductance value was increased slightly to realize minimum output voltage distortion at a $20 \mathrm{kHz}$ switching frequency. The circuit model transformer leakage and magnetizing inductance values were the same as measured on the testbed. The EASY5 inverter circuit and testbed inverter circuit parameters were as follows:

\begin{tabular}{l|l|l} 
PARAMETER & EASY5 & TESTBED \\
\hline $\mathrm{E}_{\mathrm{in}}$ & $160 \mathrm{Vdc}$ & $160 \mathrm{Vdc}$ \\
$\mathrm{L}$ & $17.16 \mu \mathrm{H}$ & $16.0 \mu \mathrm{H}$ \\
$\mathrm{C}_{\mathrm{r}}$ & $1.71 \mu \mathrm{F}$ & $1.71 \mu \mathrm{F}$ \\
$\mathrm{C}_{\mathrm{S}}$ & $2.0 \mu \mathrm{F}$ & $2.0 \mu \mathrm{F}$ \\
$\mathrm{L}_{\mathrm{m}}$ (magnetizing) & $1.3 \mathrm{mH}$ & $0.9-1.3 \mathrm{mH}$ \\
$\mathrm{L}_{\text {leak }}$ (leakage) & $1.89 \mu \mathrm{H}$ & $1.8 \mu \mathrm{H}$
\end{tabular}


The relationship between the inverter normalized switching frequency and its output voltage distortion was investigated by varying the switching frequency $f_{S}$ in the simulations while keeping the circuit parameters fixed. The inverter resonant frequency was calculated from Mapham's defining relationship of equation (1) below. The switching frequency was normalized by dividing it by the resonant frequency according to equation (2) below. The resultant inverter output voltage distortion was obtained from a Virginia Polytechnic Institute developed macro for EASY5.

$f_{r} \equiv$ resonant frequency $=\frac{1}{2 \pi \sqrt{L_{r} C_{r}}}$

$f_{s} \equiv$ switching frequency

$f_{s n} \equiv$ normalized switching frequency $=\frac{f_{s}}{f_{t}}$

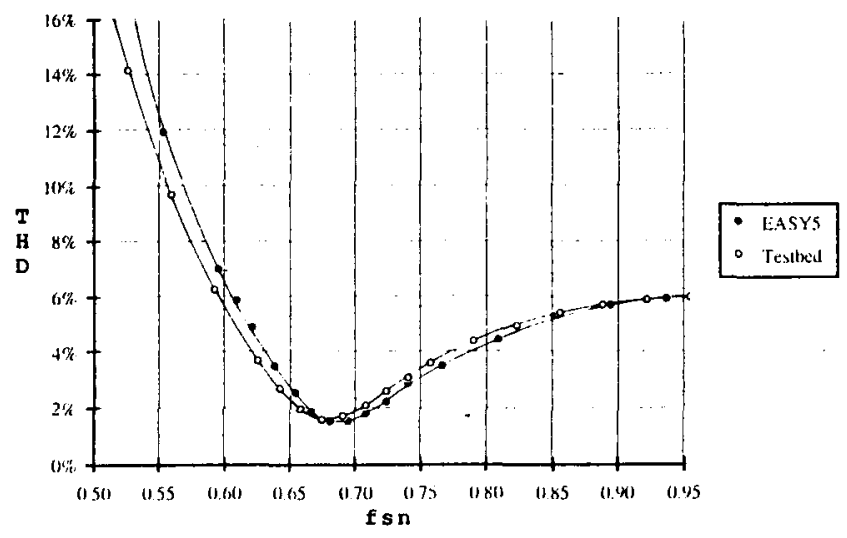

a.

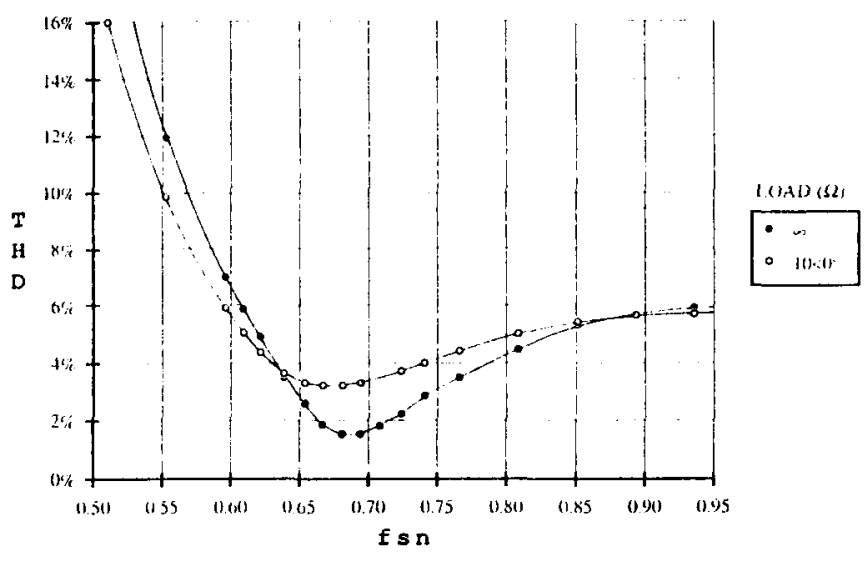

b.

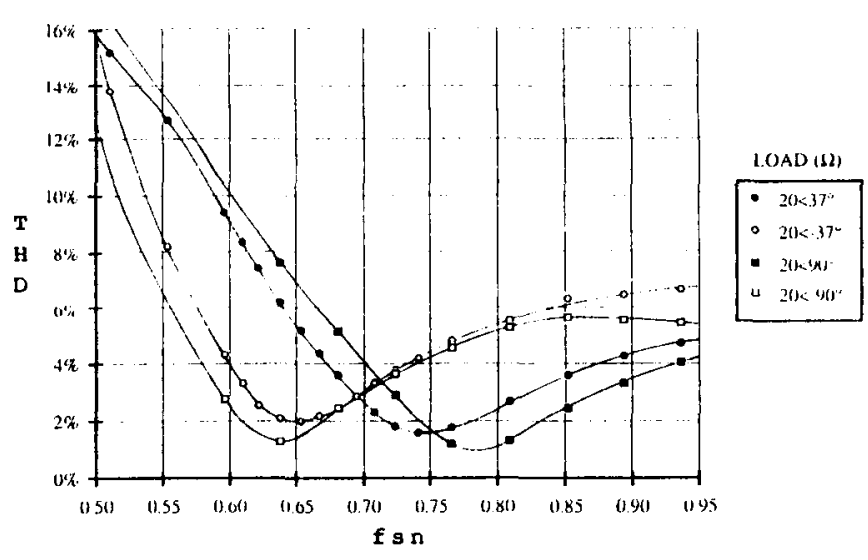

c.

Figure 3-2. Mapham inverter output voltage Total Harmonic: Distortion (THD) as a function of its switching-to-resonant frequency ratio $f_{s n}$ from the EASYS simulations: (a) Open circuit with testbed data, (b) No load and $10 \mathrm{ohm}$ resistive load, (c) 0.8 and 0.0 power factor reactive loads. 
frequencies either higher or lower than $f_{\mathrm{sn}}=0.68$ will unnecessarily increase the system distortion and radiated EMI. The $f_{s n}$ value of 0.68 is also a good practical value, because it allows inverter to be loaded to near the critical damping point. This results in maximum efficiency, because the flyback diode current is near zero which reduces losses.

\subsection{Load Effects on THD}

It has been determined that both load magnitude and power factor increase the Mapham inverter output voltage distortion [6][8][11]. THD as a function of load kVA was characterized

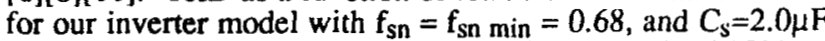
and $3.5 \mu \mathrm{F}$. Figure 3-3 shows a plot of THD vs load $k V A$ at $1.0,0.8$ leading, and 0.8 lagging power factors. It can be seen that non-unity power factor loads increase the inverter distortion more than resistive loads. This is because the reactive component combines with the resonant capacitor $C_{r}$ and changes the inverter resonant frequency, thereby de-tuning $f_{s n}$ min from the 0.68 value determined in the no load case. Such an effect should produce a new $\mathrm{f}_{\mathrm{sn} \min }$ value different from 0.68 for reactive loads.

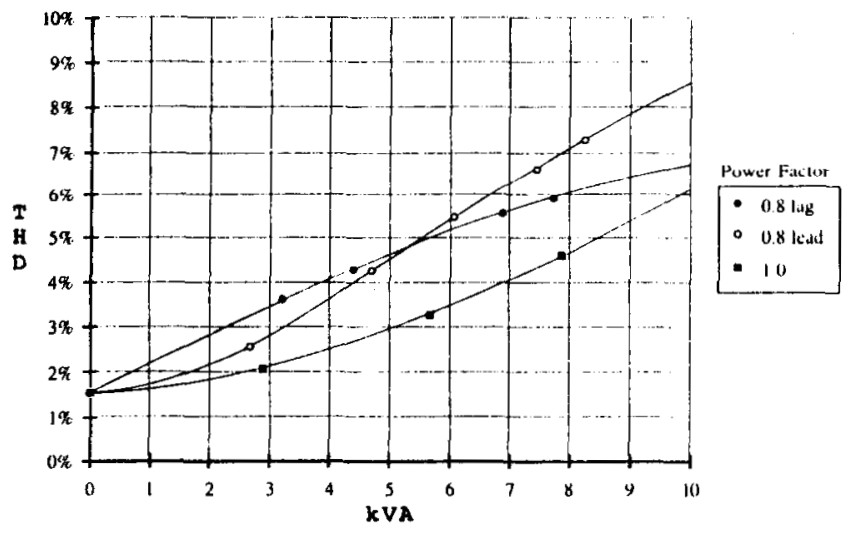

a. $-2.0 \mu \mathrm{F}$ series capacitor

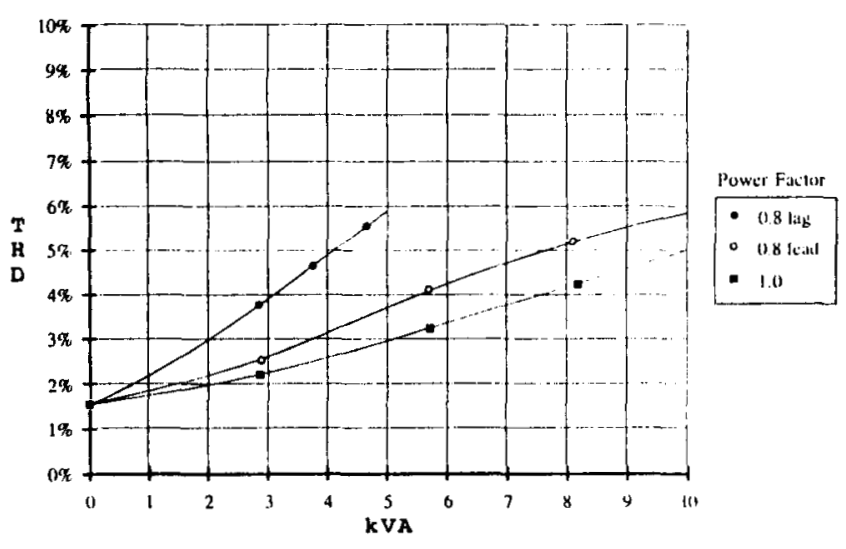

b. $-3.5 \mu \mathrm{F}$ series capacitor

Figure 3-3. Mapham inverter output voltage distortion vs. load $k V A$ for series capacitor values of: (a) $2.0 \mu F$, (b) $3.5 \mu F$.

\subsection{Load Effects on $f_{\text {sn }}$ in}

To determine whether load has an effect on the THD vs. $f_{S n}$ function, the simulations were repeated for the inverter loaded with resistive, capacitive, and inductive loads. The load impedances, load power factors, inverter kVA outputs $\left(S_{0}\right)$ at $f_{s n}=0.68\left(f_{s}=20 \mathrm{kHz}\right), f_{s n} \min$, and THD values are listed below:

\begin{tabular}{l|l|l|c|c} 
LOAD & p.f. & So@ fsn $=0.68$ & fsn min & THD@ fsn min \\
\hline$\infty \Omega$ & -- & $0.0 \mathrm{kVA}$ & 0.68 & $1.53 \%$ \\
$10 \Omega$ & 1.0 & $5.7 \mathrm{~kW}$ & 0.67 & $3.23 \%$ \\
$20 \Omega$ & 0.8 lead & $2.6 \mathrm{kVA}$ & 0.65 & $2.01 \%$ \\
$20 \Omega$ & 0.8 lag & $3.2 \mathrm{kVA}$ & 0.74 & $1.60 \%$ \\
$20 \Omega$ & 0.0 lead & $2.4 \mathrm{kVA}$ & 0.63 & $1.25 \%$ \\
$20 \Omega$ & 0.0 lag & $3.5 \mathrm{kVA}$ & 0.77 & $1.20 \%$
\end{tabular}

Figure 3-2b shows a plot of inverter THD vs $\mathbf{f}_{\mathrm{Sn}}$ for opencircuit and 10 ohm resistive loads. As can be seen from the figure, the resistance increases the minimum distortion value and aiso desensitizes the effect of $f_{\text {Sn }}$ on THD. Minimum distortion still occurs at $f_{\mathrm{Sn}}=0.68$, but the curve is flat for $f_{\mathrm{sn}}$ yalues between 0.65 and 0.70 . This result suggests that for systems with well-controlled power factors, the $f_{s n}$ value of 0.68 is not as critical, but still achieves minimum distortion.

Figure 3-2c shows plots of THD vs $f_{\mathrm{sn}}$ for the 0.8 and 0.0 power factor load cases. Note that the pure reactive loads slightly decrease the minimum THD. In contrast to the resistive load case, pure reactive loads also shift $\mathrm{f}_{\text {sn } \min }$. Inductive loads

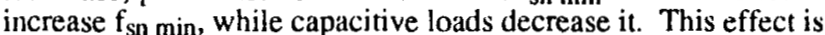
as predicted: the reactive load elements de-tune the switching-toresonant frequency ratio by combining with the resonant capacitor $\mathrm{C}_{r}$ and effectively changing the inverter resonant frequency.

The 0.8 power factor loads of figure $3-2 \mathrm{c}$ both shift $f_{\mathrm{sn} \text { min }}$ and slightly increase the minimum THD value. It appears reasonable that the resistive portion of the load increases the distortion, while the reactive portion of the load shifts the $f_{s n}$ min point.

The results in figures $3-2 b$ and 3-2c were obtained with a series capacitor value of $2.0 \mu \mathrm{F}$ because it was the value used in the testbed inverters, and also because frequency domain analysis predicted a $2.0 \mu \mathrm{F}$ capacitor would realize the lowest inverter output impedance and best inherent regulation [7]. As is discussed in section 4 , the series capacitor affects the THD under load, so the loaded inverter THD vs $f_{\text {Sn }}$ results presented in this section will be slightly different for other series capacitor values. However, since the load impedances used resulted in moderate inverter loading and since the series capacitor effects become more pronounced at higher kVA levels, the difference is small. Some simulations were repeated using a $3.5 \mu \mathrm{F}$ series capacitor, and the results were nearly identical with the $2.0 \mu \mathrm{F}$ capacitor results.

\section{SERIES CAPACITOR EFFECTS ON INVERTER PERFORMANCE}

\subsection{Series Capacitor Effects on Regulation}

As noted in the introduction, the series capacitor $C_{s}$ lowers the inverter output impedance. Referring to the frequency domain Mapham inverter model of figure 4-1a and neglecting the leakage inductance and magnetizing inductance, the output impedance $Z_{o}$ at the switching frequency $\omega_{s}=2 \pi f_{S}$ is given by:

$\bar{Z}_{0}=j Z_{0}=\frac{j\left(\omega_{s} I\right.}{1-\omega_{s n}^{2}}$ 


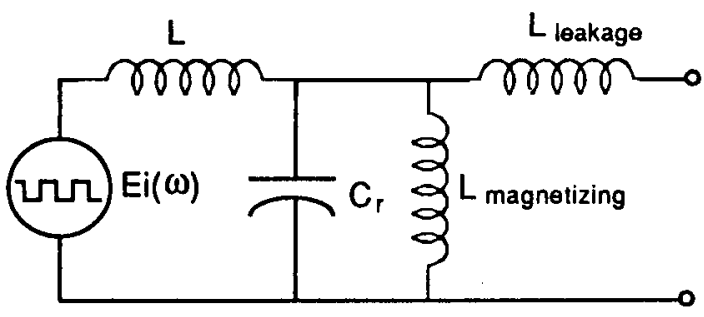

a.

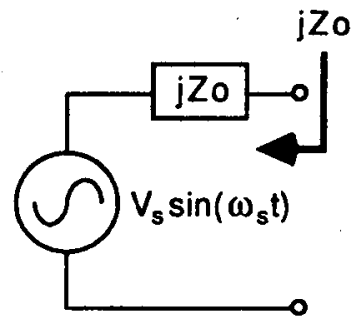

b.

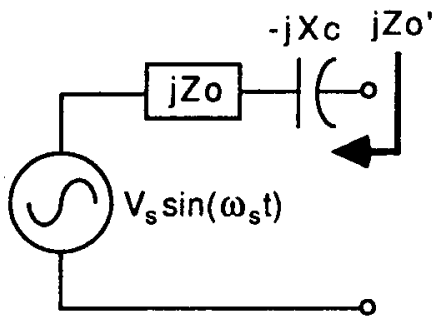

c.
Figure 4-1. Mapham inverter simplified frequency domain model (a), equivalent Thevenin circuit at $20 \mathrm{kHz}(b)$, equivalent Thevenin circuit with series capacitor compensation $(c)$.

Since $\omega_{\mathrm{Sn}}\left(=\mathrm{f}_{\mathrm{sn}}\right)$ is less than 1 in a Mapham inverter $(0.68$ for our EASY 5 inverter model), equation (3) is positive and $j Z_{0}$ is inductive. Figure 4-1b represents a simplified Thevenin voltage source equivalent circuit at the switching frequency $\omega_{\mathrm{s}} . j \mathrm{Z}_{\mathrm{o}}$ represents the inductive source impedance given by equation (3). To cancel the inductance, a negative impedance $-j X_{c}$ equal in magnitude to $\mathrm{j} \mathrm{Z}_{\mathrm{o}}$ can be introduced in series with the inverter to form a new source impedance $j Z_{0}^{\prime}$, as shown in figure 4-1c. The value of series capacitor has been determined by Oruganti [7], and is derived as follows:

$-j X_{c}=-j \frac{1}{\omega_{s} C_{s}}$

$j Z_{o}^{\prime}=j Z_{o}-j X_{c}=\frac{j \omega_{s} L}{1-\omega_{s n}^{2}}-j \frac{1}{\omega_{s} C_{s}}$

$C_{s}\left(j Z_{0}^{\prime}=0\right)=\frac{1-\omega_{s n}^{2}}{\omega_{s}^{2} L}=\frac{1-\omega_{s n}^{2}}{\omega_{s n}^{2}} C_{r}$

For our optimized inverter with $\omega_{\mathrm{sn}}=0.68$ and $\mathrm{C}_{\mathrm{r}}=1.71 \mu \mathrm{F}$, the series capacitor $C_{s}\left(j Z_{0}{ }^{\prime}=0\right)$ was calculated from equation (6) to be almost exactly $2.0 \mu \mathrm{F}$. Therefore, for $C_{s}=2.0 \mu \mathrm{F}$, equations (5) and (6) predict that the inverter output impedance should be near zero which should yield the best load regulation. This follows from approximate voltage drop analysis for an $\mathrm{AC}$ system with a source impedance of $\mathrm{jZ}_{\mathrm{o}}$ and a load impedance of $\mathrm{R}_{\mathrm{L}}+\mathrm{j} \mathrm{X}_{\mathrm{L}}$ :

$$
\begin{aligned}
& \bar{V}_{L}=\bar{V}_{s} \frac{\left(R_{L}+j X_{L}\right)}{\left.\mid R_{L}+j X_{L}\right)+j Z_{o}^{\prime}} \\
& \left.\bar{V}_{L}\right\rfloor=\sqrt{V_{s}} \frac{\sqrt{R_{L}^{2}+X_{L}^{2}}}{\sqrt{R_{L}^{2}+\left(x_{L}+Z_{o}\right)^{2}}}
\end{aligned}
$$

If $Z_{0}^{\prime}=0$, then $\left|V_{L}\right|=\left|V_{s}\right|$. However, if $Z_{0}{ }^{\prime} \neq 0$, then equation (7) predicts either a load voltage drop or rise, depending on the respective signs of $Z_{0}$ and $X_{L}$. If $X_{L}$ and $Z_{0}$ ' are the same sign in equation (7), then $\left(X_{L}+Z_{0}{ }^{\prime}\right)^{2}>X_{L}{ }^{2}$ and $\left|V_{\mathrm{V}}\right|<\mid V_{\S}$ resulting in a load voltage drop. If $X_{L}$ and $Z_{0}^{\prime}$ are of opposite sign, then $\left(X_{L}+Z_{0}\right)^{2}<X_{L}{ }^{2}$ and $\left|V_{V}\right|>\mid V_{S}$, resulting in a load voltage rise. For $C_{S}>C_{S}\left(j Z_{0}=0\right)$, the impedance $j X_{c}$ introduced by $C_{s}$ in equation (4) is smaller than the inductive inverter output impedance $\mathrm{jZ}_{0}$, and $\mathrm{jZ}_{\mathrm{o}}{ }^{\prime}$ will be positive or inductive from equation (5). Conversely, if the series capacitor $\mathrm{C}_{\mathrm{s}}$ is smaller than $\mathrm{C}_{\mathrm{s}}\left(\mathrm{jZ_{0 }}{ }^{\prime}=0\right)$, the impedance $\mathrm{jX}$ of equation (4) will be larger than $j Z_{0}$, and $j Z_{0}^{\prime}$ will be negative or capacitive.

To verify the prediction - of equations (3-7), circuit simulations were performed using a range of series capacitor values at 1.0, 0.8 leading, and 0.8 lagging power factor load impedances. Figure 4-2 shows plots of inherent inverter output voltage regulation vs. output kVA. The inductive impedance $\mathrm{j} \mathrm{Z}_{0}$ of the uncompensated Mapham inverter is verified when $\mathrm{C}_{s}=\infty$ (no series capacitor) or $6 \mu \mathrm{F}\left(\mathrm{jX}_{\mathrm{c}}\right.$ is small). Inductive loads cause a voltage drop (figure 4-2c), while capacitive loads cause a voltage rise (figure $4-2 b$ ). For $C_{s}<C_{s}\left(j Z_{0}{ }^{\prime}=0\right)$, the inverter impedance is overcompensated and turns capacitive, as can be verified for the $C_{s}=1.0 \mu \mathrm{F}$ case. Inductive loads now result in a voltage rise while capacitive loads result in a voltage drop. These effects are as predicted by equation (7).

It can also be seen from figure 4-2 that near perfect load regulation is achieved for series capacitor values around $3.5 \mu \mathrm{F}$ at all power factors. The voltage regulation curve is within $2.5 \%$ up to $6 \mathrm{kVA}$ for the resistive, capacitive, and inductive loads. Thus, the value of $\mathrm{C}_{S}\left(j Z_{0}^{\prime}=0\right)$ determined from the simulations is close to $3.5 \mu \mathrm{F}$, and $\mathrm{j} \mathrm{Z}_{\mathrm{o}}$ ' does appear to be close to zero. However, the $3.5 \mu \mathrm{F}$ value of $\mathrm{C}_{\mathrm{S}}\left(\mathrm{j} \mathrm{Z}_{\mathrm{o}}{ }^{\prime}=0\right)$ does not agree with the predictions of equation (6), which gave a value of $\mathrm{C}_{\mathrm{S}}\left(\mathrm{jZ}_{0}{ }^{\prime}=0\right)=2.0 \mu \mathrm{F}$. Tsai and Lee $[8]$ used a value of $\mathrm{L} / 2 \mathrm{in}$ place of $\mathrm{L}$ in equation (5) and (6), which gives a value of $\mathrm{C}_{\mathrm{s}}\left(\mathrm{j} \mathrm{Z}_{\mathrm{o}}{ }^{\prime}=0\right)=5.7 \mu \mathrm{F}$ for our inverter model, which also does not agree with the simulation results. Since the $3.5 \mu \mathrm{F}$ value of $\mathrm{C}_{\mathrm{s}}\left(\mathrm{jZ} \mathrm{Z}_{\mathrm{o}}{ }^{\prime}=0\right)$ falls in between both values calculated from the Mapham inverter simplified frequency domain model, it can be concluded that neither $\mathrm{L}$ nor $\mathrm{L} / 2$ is the proper frequency domain circuit-inductance value. A closer look into the inverter operation is necessary to determine why the analysis does not accurately predict the inverter impedance, and what corrections, if any, can be made to the frequency domain inverter model of figure 4-1 a to improve its accuracy.

\section{Effective Inductance}

One explanation for the shortcomings of equation (6) is that the equivalent inverter inductance is not equal to $\mathrm{L}$ or $\mathrm{L} / 2$. A look into the three inverter conduction mode states will illustrate this point. Referring to figure 4-3, the three inverter conduction modes $M 1, M 2, M 1$ are shown. During steady-state operation, the inverter passes through the sequence M2-M1-M2-M1' during each cycle. During conduction mode $M 2$, the two inductors on either side of the resonant capacitor $C_{r}$ are effectively in parallel, and the circuit inductance is $L / 2$. During conduction modes $\mathrm{M} 1$ and $\mathrm{M} 1$ ', the circuit inductance is equal to $\mathrm{L}$. Thus, the circuit inductance alternates between $\mathrm{L}$ and $\mathrm{L} / 2$ during every half-cycle. The equivalent or effective inductance will therefore be a complex average of $L$ and $L / 2$, and varies as a function of $f_{\text {sn }}$ and load.

The dependence of the effective inductance on $f_{\mathrm{sn}}$ caused the steady-state resonant inductor conduction period $T_{\text {rss }}$ to vary with $f_{\mathrm{sn}}$. Defining the equivalent or effective inductance $L_{c f f}$ as the value of inductance that resonates with the inverter capacitor $C_{r}$ at a period of $T_{r s s}$, the following equation results: 


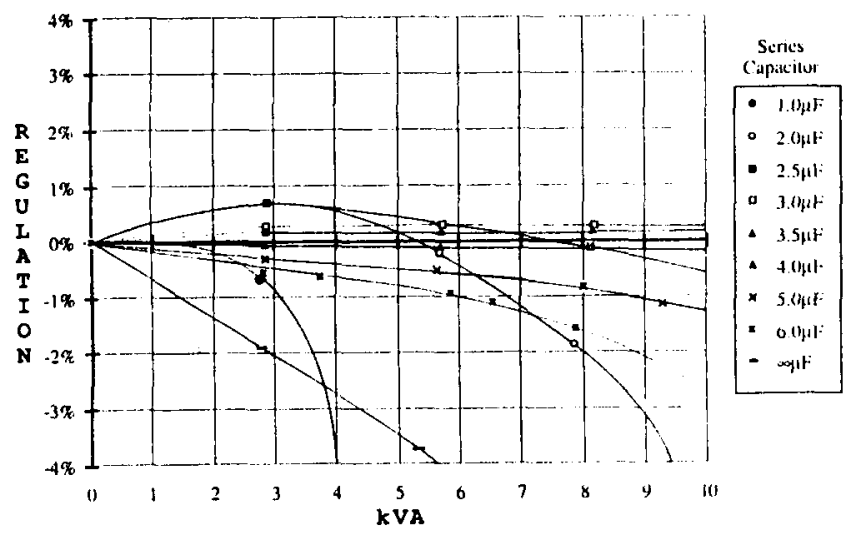

a. -1.0 power factor

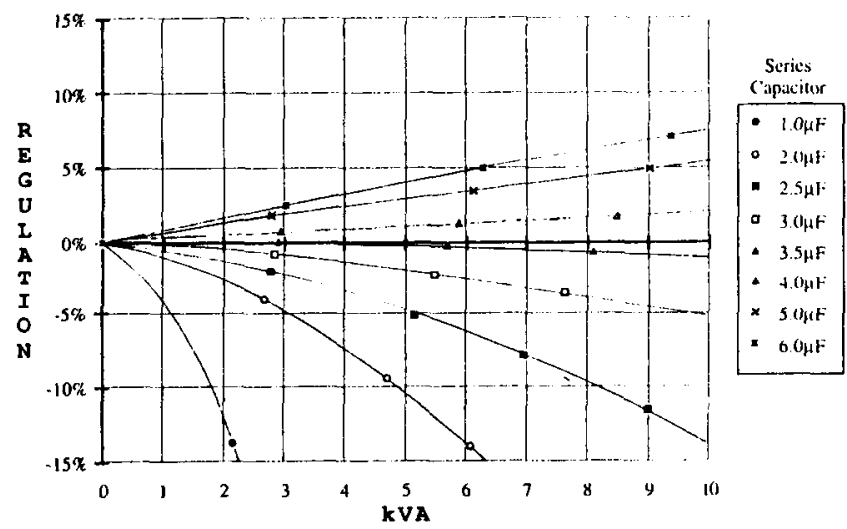

b. -0.8 leading power facior

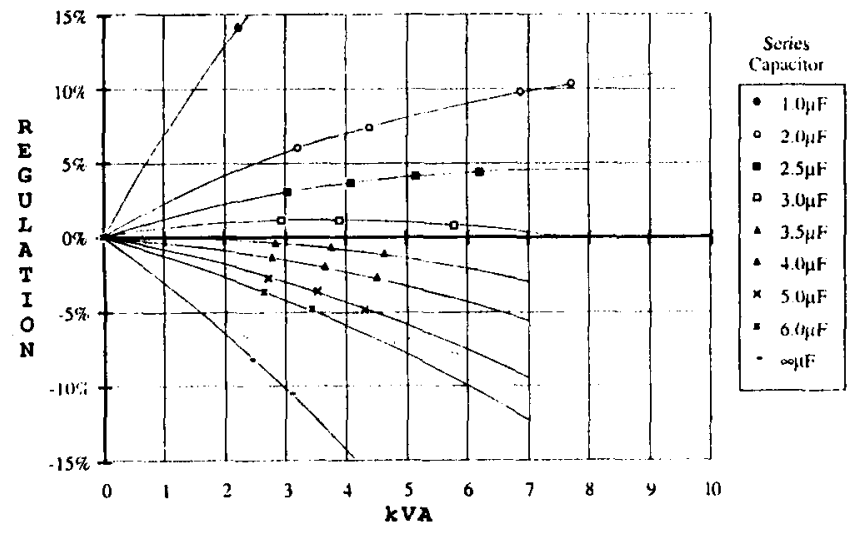

c. -0.8 lagging power fuctor

Figure 4-2. Mapham inverter inherent voltage regulation vs output kVA for different series capacitor values at: (a) unity $p . f ., \quad(b) 0.8$ leading $p . f .,(c) 0.8$ lagging $p . f$.

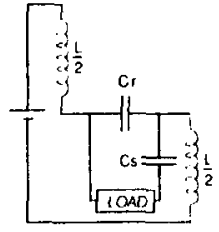

M1

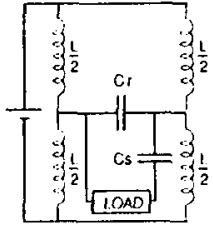

M2

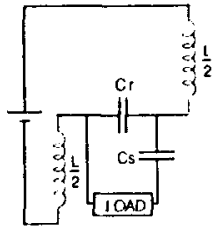

M1
Figure 4-3. Normal conduction modes of the Mapham inverter.

$L_{\mathrm{cff}}=\frac{\mathrm{T}_{\mathrm{rss}}^{2}}{(2 \pi)^{2} \mathrm{C}_{\mathrm{r}}}$

Equation (8) is only valid at no load. A detailed discussion of $L_{\text {elf }}$ and the load effects on $L_{\text {ell }}$ can be found in reference [12|.

\subsection{Series Capacitor Effects on THD}

The distortion effects of the series capacitor were also investigated, at unity, 0.8 leading, and 0.8 lagging power factor loads. Figure 4-4 shows plots of THD vs. load kVA for series capacitor values between $1.0 \mu \mathrm{F}$ and $\infty \mu \mathrm{F}$ (no series capacitor). For the unity power factor loads in 4-4a, series capacitor values between $2.5 \mu \mathrm{F}$ and $4.0 \mu \mathrm{F}$ reduce THD. However, the difference in THD between $2.0 \mu \mathrm{F}$ and $\propto \mu \mathrm{F}$ series capacitors is small. Thus for resistive loads, the effect of the series capacitor on THD is not very significant.

For 0.8 leading power factor loads, as shown in $4-4 \mathrm{~b}$, the series capacitor increases distortion. However, for large series capacitor values including $\mathrm{C}_{\mathrm{S}}\left(\mathrm{jZ}_{\mathrm{O}}{ }^{\prime}=0\right)=3.5 \mu \mathrm{F}$, the increase in THD is insignificant. The value $\mathrm{C}_{S}\left(\mathrm{jZ}_{\mathrm{O}}{ }^{\prime}=0\right)=3.5 \mu \mathrm{F}$ results in a THD value of about $4.2 \%$ at $6 \mathrm{kVA}$, which is close to the minimum THD value at $6 \mathrm{kVA}$ of $4.0 \%$ for the $6.0 \mu \mathrm{F}$ capacitor.

For 0.8 lagging power factor loads, the series capacitor decreases distortion, but the actual THD is higher at a given KVA than for leading power factor loads. For $\mathrm{C}_{\mathrm{s}}\left(\mathrm{j}_{\mathrm{O}}{ }^{\prime}=0\right)=3.5 \mu \mathrm{F}$, the distortion at $6 \mathrm{kVA}$ was about $7 \%$-- almost $3 \%$ higher than for a $6 \mathrm{kVA}$ leading 0.8 power factor load. A more significant benefit of the series capacitor is that it increases the kVA output capability of the inverter for lagging power factor loads.

Despite the benefits of the series capacitor in improving regulation, additional output filtering may be required, depending on the THD requirements of the $20 \mathrm{kHz}$ system. The current flight design for the Space Station MIU replaces the series capacitor with a more complex filter to further reduce THD. The additional output filter can also be designed to eliminate the harmonic circulating currents in paralleled inverters, which result from the high frequency impedance zero due to the series combination of the output transformer leakage inductance and the series and resonant capacitors [12].

\subsection{Series Capacitor Effects on Short Circuit Operation}

One disadvantage of the $3.5 \mu \mathrm{F}$ series capacitor is that the inverter will not inherently run into a short circuit, as it will for small series capacitor values as reported by Mapham [3]. Additional fault protection circuitry will therefore be required to limit the semiconductor switch current into the resonant tank/load network in the event of a load fault. One fault protection scheme is to utilize clamped mode operation. Upon 


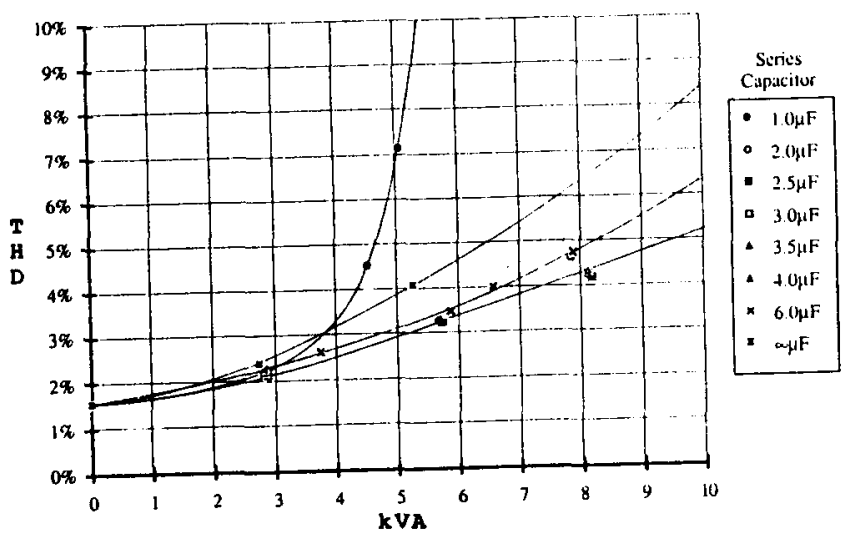

a. - 1.0 power factor

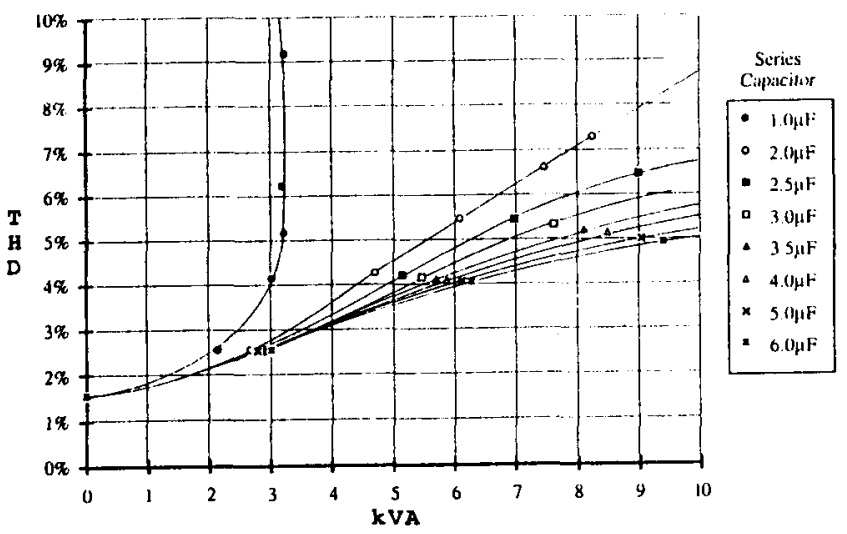

b. -0.8 leading power factor

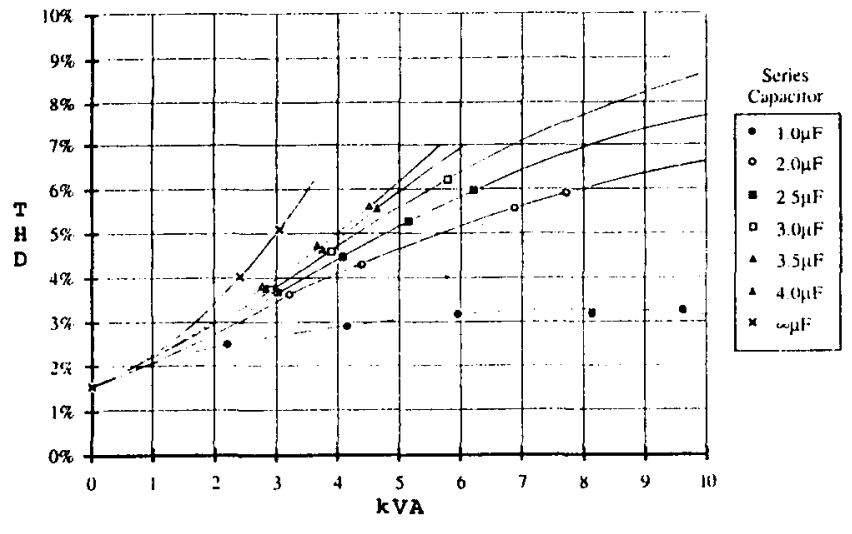

c. - 0.8 lagging power factor

Figure 4-4. Mapham inverter output voltage THD vs. output $k V A$ for different series capacitor values at: (a) unity p.f., (b) 0.8 leading $p . f .$, (c) 0.8 lagging $p . f$.

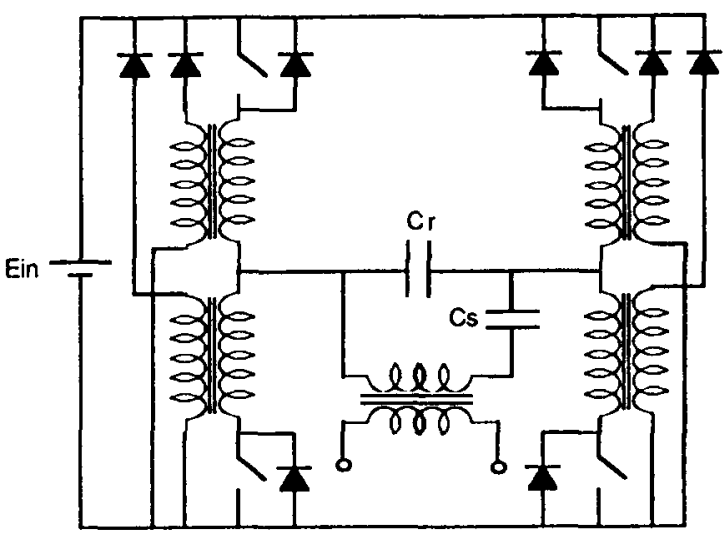

Figure 4-5. The Mapham inverter can be modified to drive a short-circuit by using turn-off switches and incorporating a secondary winding to return the stored inductor energy to the power supply during forced switch commutation.

detection of a fault, the switch on time is controlled to limit the current into the resonant tank. This method also actively limits the inverter short circuit output current.

To implement clamped mode operation in a Mapham inverter, forced switch commutation is required while the inductor is carrying current. This will produce large voltage transients across the semiconductor switches which can destroy the devices. To eliminate this potential problem, a secondary winding on the resonant inductors can be employed to return the stored inductor energy to the power supply, as shown in figure 4-5. If the voltage across the inductor exceeds the power supply voltage, the secondary winding diodes turn on and the stored magnetizing energy is returned to the stipply.

\section{CONCLUSIONS}

- The EASY5 total harmonic distortion analysis agreed with hardware test results, and proved useful as a tool for characterizing the distortion of a Mapham inverter.

- A switching-to-resonant frequency ratio of 0.68 results in minimum output voltage distortion for an unloaded Mapham inverter.

- The minimum distortion switching-to-resonant frequency ratio was found to change with reactive loads. This is because the reactive component of the load combines with the resonant capacitor and changes the inverter resonant frequency.

- Selection of proper series capacitor can improve the inherent load regulation of a Mapham inverter to better than 3\% for 0.8 leading to 0.8 lagging power factor loads up to $6 \mathrm{kVA}$.

- Frequency domain analysis using an effective inverter inductance equal to either $L$ or $L / 2$ does not accurately predict optimum series capacitor for regulation.

- An effective resonant inductance, Leff was proposed to improve the accuracy of the frecuency domain Mapham

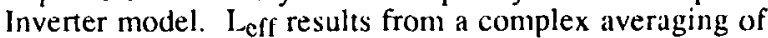
the three inverter conduction modes. 
- Overall, the series capacitor results in a small improvement in THD, but more significantly increases the kVA output for lagging power factor loads. Additional filtering should be used to reduce THD.

- A Mapham inverter can be modified to operate into a short circuit if clamped mode operation is used. Additional windings on the inductors are required to return the stored inductor energy to the power supply during forced switch commutation.

\section{REFERENCES}

[1] "In Space, it's 20-kHz AC Power," J. Mildice, Powertechnics Magazine, February, 1989.

[2] "Space Station $20 \mathrm{kHz}$ Power Management and Distribution System," I.G. Hansen and G.R. Sundberg, PESC Conference Record, June, 1986.

[3] "An SCR Inverter with Good Regulation and Sine-Wave Output," N. Mapham, IEEE Transactions on Industry and General Applications, MAR/APR, 1967.

[4] "AC Power System Testbed, Final Report," J. Mildice and R. Sundberg, NASA CR 175068, November, 1988.

[5] "Development and Testing of a $20 \mathrm{kHz}$ Component Testbed," R. Button, A. Brush, and R. Sundberg, 24th IECEC Conference Record, August, 1989.
16] "Main Inverter Unit (MIU) Efficiency Test Report - Phase II" R. Sundberg, General Dynamics Space Systems Division Rpt \# 8721-88-021, May, 1988.

[7] "A Filter Approach to the AC Bus Systems," R. Oruganti, EE6400 Project Report, Virginia Polytechnic Institute and State University, June, 1985.

181 "Effects of Load on the Performance of a Mapham Resonant Inverter," F. Tsai and F. Lee, Virginia Polytechnic Institute and State University, 23rd IECEC Conference Record, September, 1988.

[9] "EASY5 Engineering Analysis System User's Guide," Boeing Computer Services Company, April, 1983.

[10] "Computer Modeling and Simulation of a $20 \mathrm{kHz} \mathrm{AC}$ Distribution System for Space Station," F. Tsai and F. Lee, 22nd IECEC Proceedings, 1987.

[11] "Main Inverter Unit (MIU) Distortion Test Report," $R$. Sundberg, A. Brush, and A. Patterson, NASA PIR 220, November, 1988

112| "Frequency Domain Model for Analysis of Paralleled, Series-Output Connected Mapham Inverter Pairs," A Brush, R. Sundberg, and R. Button, 24th IECEC Conference Record, August, 1989. 


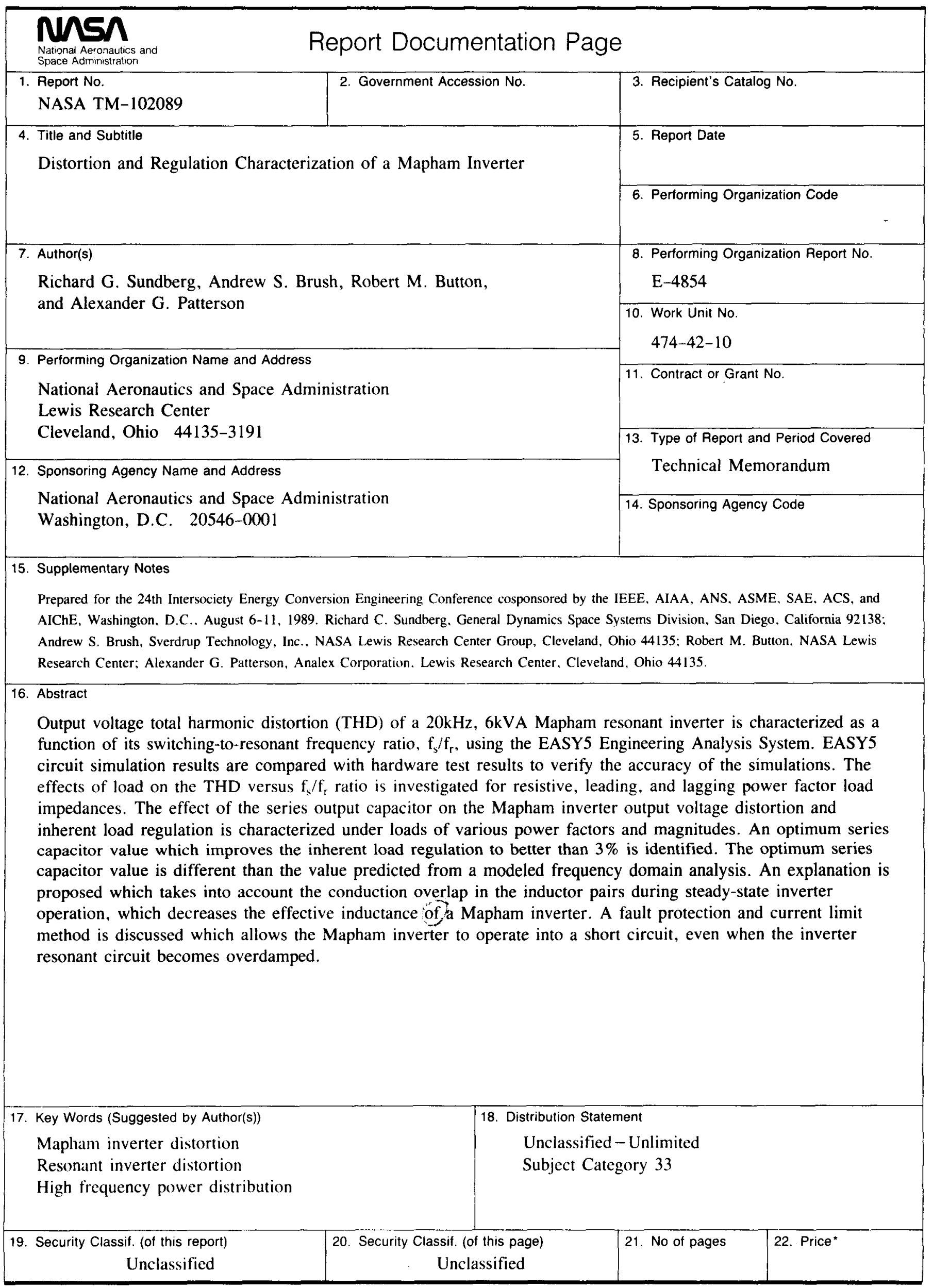

